\title{
Perspectiva da família na visita domiciliar do enfermeiro ao idoso na Atenção Primária de Saúde
}

\author{
Perspective of the family during home visits by nurses to the elderly in Primary Health Care \\ Perspectiva de la familia durante las visitas domiciliarias del enfermero a los ancianos en Atención \\ Primaria de Salud \\ Wanderson Alves Ribeiro ${ }^{*}$, Juliana de Lima Gomes ${ }^{2}$, Roberta Gomes Santos Oliveira ${ }^{3}$, Larissa
Meirelles de Moura ${ }^{4}$, Raimunda Farias Torres Costa
}

Como citar esse artigo. Ribeiro, WA; Gomes, JL; Oliveira, RGS; de Moura, LM; Costa, RFT. Perspectiva da família na visita domiciliar do enfermeiro ao idoso na Atenção Primária de Saúde. Revista Pró-UniverSUS. 2020 Jul./Dez.; 11 (2): 02-09.

\section{Resumo}

Trata-se de um estudo qualitativo, exploratório, descritivo e de pesquisa de campo que objetivou em compreender a ótica da família frente à visita domiciliar do enfermeiro na atenção primaria: Repercussões do processo de envelhecimento do idoso. Como metodologia, após a aplicação da entrevista semiestruturada, buscou-se utilizar de forma sistemática a aplicação da técnica de análise de conteúdo alicerçada nas bases conceituais legitimadas na obra de Bardin. O número de sujeitos alcançados ao final da coleta de dados foi de 17 indivíduos e, posteriormente, emergiram três categorias: A avaliação do atendimento do enfermeiro na visita domiciliar na percepção do familiar; Relação a confiabilidade dos cuidados impostos pelo enfermeiro; e A dificuldade em entender as orientações do enfermeiro. Conclui-se que o familiar que cuida, precisa ter um acompanhamento periodicamente de acordo com a atenção necessária ao seu familiar, é importante que o enfermeiro esteja plenamente consciente não apenas de suas responsabilidades técnicas dentro da visita domiciliar, mas também de suas responsabilidades bióticas. Devemos salientar a necessidade de serviços de saúde abrangentes, não apenas curativos, mas também serviços que atendam às necessidades em termos de promoção da saúde, prevenção, reabilitação e tratamento de condições comuns. Pois um nível resolutivo de atenção primária de saúde é a base para o desenvolvimento de sistemas de saúde.

Palavras-chave: Idoso, Enfermagem, Família.

\begin{abstract}
This is a qualitative, exploratory, descriptive and field research study that aimed to understand the family's perspective of the nurse's home visit in primary care: Repercussions of the aging process of the elderly. As a methodology, after applying the semistructured interview, we sought to systematically use the application of the content analysis technique based on the conceptual bases legitimized in Bardin's work. The number of subjects reached at the end of the data collection was 17 individuals and, subsequently, three categories emerged: The assessment of nurses' attendance at home visits in the perception of the relative; Relation to the reliability of the care imposed by the nurse; and the difficulty in understanding the nurse's guidelines. It is concluded that the family member who cares, needs to be monitored periodically according to the necessary attention to his family, it is important that the nurse is fully aware not only of his technical responsibilities within the home visit, but also of his biotic responsibilities. We must emphasize the need for comprehensive health services, not only dressings, but also services that meet the needs in terms of health promotion, prevention, rehabilitation and treatment of common conditions. For a resolutive level of primary health care is the basis for the development of health systems.

Keywords: Elderly, Nursing. Family.
\end{abstract}

\section{Resumen}

Se trata de un estudio cualitativo, exploratorio, descriptivo y de campo de investigación que tuvo como objetivo comprender la perspectiva familiar de la visita domiciliaria del enfermero en atención primaria: Repercusiones del proceso de envejecimiento del anciano. Como metodología, luego de aplicar la entrevista semiestructurada, se buscó utilizar sistemáticamente la aplicación de la técnica de análisis de contenido a partir de las bases conceptuales legitimadas en el trabajo de Bardin. El número de sujetos alcanzados al final de la recolección de datos fue de 17 individuos y, posteriormente, surgieron tres categorías: La valoración de la asistencia de enfermeras a las visitas domiciliarias en la percepción del familiar; Relación con la confiabilidad del cuidado impuesto por la enfermera; y La dificultad para comprender las pautas de la enfermera. Se concluye que el familiar que atiende, necesita ser monitoreado periódicamente de acuerdo a la atención necesaria a su familia, es importante que el enfermero sea plenamente consciente no solo de sus responsabilidades técnicas dentro de la visita domiciliaria, sino también de sus responsabilidades bióticas. Debemos enfatizar la necesidad de contar con servicios integrales de salud, no solo apósitos, sino también servicios que satisfagan las necesidades en cuanto a promoción de la salud, prevención, rehabilitación y tratamiento de condiciones comunes. Para un nivel resolutivo la atención primaria de salud es la base para el desarrollo de los sistemas de salud.

Palabras clave: Ancianos, Enfermería, Familia.

Afiliação dos autores:

${ }^{1}$ Enfermeiro. Docente do Curso de Graduação da UNIG e UCB. Mestre pelo Programa Acadêmico em Ciências do Cuidado em Saúde pela Escola de Enfermagem Aurora de Afonso Costa da UFF, Niterói/RJ. Brasil. E-mail: nursing_war@hotmail.com ORCID: https://orcid.org/0000-0001-8655-3789

${ }^{2}$ Enfermeira. Graduada pela Universidade Iguaçu. Brasil. E-mail: juliana.limag@hotmail.com ORCID: https://orcid.org/0000-0002-4907-1710

${ }^{3}$ Enfermeira. Graduada pela Universidade Iguaçu. Brasil. E-mail: roberta.enferm93@hotmail.com ORCID: https://orcid.org/0000-0003-0076-1507

${ }^{4}$ Enfermeira. Graduada pela Universidade Iguaçu. Brasil. E-mail: larissa00meirelles@gmail.com ORCID: https://orcid.org/0000-0002-9127-8563

${ }^{5}$ Enfermeira. Graduada pela Universidade Iguaçu. Brasil. E-mail: dinhaftcosta@gmail.com ORCID: https://orcid.org/0000-0001-7325-3138

* Email de correspondencia: nursing_war@hotmail.com 


\section{Introdução}

A motivação pelo qual alentou o desenvolvimento desta pesquisa, surgiu durante o processo de ensinoaprendizagem dos autores, na graduação de enfermagem quando pode-se vislumbrar, de forma teórica, a grande relevância da realização de visita domiciliar, como uma estratégia de cuidado e ainda, uma ação de prevenção primária. Cabe mencionar que, está inquietação ficou mais emergente quando deu-se início as atividades de estagio currículo, no âmbito de Estratégia Saúde da Família, onde foi possível evidenciar o impacto dessa ação na vida do idoso e de seus familiares.

A visita domiciliar é uma opção de cuidado que traz benefícios especialmente para os idosos com doenças incapacitantes e aqueles que dependem do auxílio de terceiros por longo

Período de tempo. Pois, essas pessoas, muitas vezes, não dispõem de umindivíduo que se responsabilize por seus cuidados diários ${ }^{1}$.

De acordo com a teoria geral de Orem, os enfermeiros são designados como agentes de autocuidado terapêutico, quando as pessoas, por si só, não têm capacidade de desenvolver o autocuidado, entra o trabalho do enfermeiro no processo de cuidar. Dessa maneira, nos cuidados domiciliários, o enfermeiro entra no espaço cultural e vivencial de cada família, o que exige uma grande capacidade de adequação, mas também de entendimento das diferentes particularidades de cada um desses espaços no sentido de conquistar a confiança das pessoas cuidadas ${ }^{2}$.

Sendo assim, refere-se que a Visita Domiciliar é um dos instrumentos mais indicados na prestação de cuidados a saúde do idoso, se caracteriza de uma forma leve, a ideia primordial é a continuação do processo de trabalho contribua para criar situações próximas da realidade na qual este usuário está inserido, de modo que estimule reflexões acerca da necessidade de ressignificar práticas, valores e atitudes ${ }^{3}$.

Através dessas visitas é verificado as medidas antropométricas, fornecem informações a respeito da alimentação saudável, prática de exercícios físicos, e a prevenção das doenças diabéticas e hipertensas ou até mesmo as complicações. As ações desenvolvidas no domicílio privilegiam tanto ações de promoção, quanto de recuperação da saúde do idoso e da família ${ }^{3}$.

Com isso, é necessária uma reflexão sobre a questão da responsabilidade e da influência do apoio da equipe de enfermagem na forma como a família lida com o advento de uma situação inesperada e que é interdependente, além das características da situação em si, do sentido dado ao evento, da sua inscrição na história familiar e ainda, do grau de resiliência da família, a qual se constrói ao longo do tempo durante o trâmite das vivências pregressas ${ }^{4}$.
Nessa perspectiva, de acordo com o Instituto Brasileiro de Geografia e Estatística (IBGE), a população de 60 anos ou mais no país corresponde a 30,2 milhões em 2017 da população total. O aumento da população idosa é uma realidade de diversos países, principalmente nos mais desenvolvidos, sendo assim existe uma grande preocupação em preservar a saúde e o bem-estar global para atender as especificidades desta etapa de vida, o idoso tem merecido atenção especial, pois o processo de envelhecer saudável implica cuidados de promoção, prevenção, educação, intervenção. Requer envolvimento e qualificação dos profissionais da atenção básica, com abordagem multiprofissional e interdisciplinar ${ }^{5}$.

Em consonância ao contexto vale embasar que, entre 2012 e 2017, a quantidade de idosos cresceu em todas as unidades da federação, sendo os estados com maior proporção de idosos o Rio de Janeiro e o Rio Grande do Sul, ambas com 18,6\% de suas populações dentro do grupo de 60 anos ou mais 6 .

Conforme o Sistema Único de Saúde (SUS) a finalidade primordial da política nacional de saúde da pessoa idosa é recuperar, manter e promover a autonomia e a independência dos idosos, obtendo medidas sendo em grupo ou individual de saúde, é considerado idoso e alvo dessas políticas todo homem ou mulher que possui 60 anos ou mais?

Referente ao que é escrito nas políticas de saúde ao idoso, os objetivos são manter ao máximo o idoso na vivência com sua família e a comunidade, seu deslocamento para um serviço de longa permanência: hospital, asilo ou similar, deve ser a última alternativa $^{8,9}$.

Não só no Brasil, mas no mundo todo vem se observando essa tendência de envelhecimento da população nos últimos anos. Ela decorre tanto do aumento da expectativa de vida pela melhoria nas condições de saúde quanto pela questão da taxa de fecundidade, pois o número médio de filhos por mulher vem caindo. Esse é um fenômeno mundial, não só no Brasil. Aqui demorou até mais que no resto do mundo para acontecer ${ }^{10}$.

Vale informar que é pertinente o cuidado individual para cada indivíduo, sendo assim reconhece a singularidade, valores, e não deixando de identificar suas características pessoais, condições clínicas, participação do autocuidado, impacta positivamente no resultado da assistência ${ }^{11}$.

A enfermagem necessita buscar o aprimoramento quanto à assistência, buscando um cuidado individual e personalizado para que exista um profissional com esse pensamento ampliado, dominando todos os programas de assistência à saúde na rede básica por ser uma área de primeiro contato à saúde ${ }^{11}$.

É necessário incluir na formação acadêmica uma metodologia problematize e que faça com que o acadêmico de enfermagem seja capaz de propor e 
executar mudanças no modelo de cuidar se tornando um enfermeiro crítico não só no âmbito hospital, mas também na rede básica de saúde, onde o cuidado é essencial, pois evita agravos à saúde e dar uma atenção ao idoso são uma tática de promover uma saúde para nossa população aumentando a qualidade de vida ${ }^{12}$.

Para tal, traçou a seguinte questão norteadora: qual a ótica da família frente a visita domiciliar ao idoso realizada pelo enfermeiro da atenção primária?

A justificativa desse estudo vem pela necessidade de perceber, na visão do familiar, a eficácia das visitas domiciliares realizadas pelos enfermeiros da atenção primária no sentido de promover a saúde e autonomia dessa população. Visando diminuir os números de internações de longa permanência por complicações de doenças de base e promovendo uma maior expectativa de vida.

Nesse sentido, o artigo tem como objetivo geral: compreender a ótica do familiar sobre o processo de envelhecimento do idoso frente a visita domiciliar realizada pelo enfermeiro e, consequentemente, como objetivos específicos: e Identificar como a atuação do enfermeiro na visita domiciliar é percebida pelo familiar do idoso e compreender a adesão do familiar referente as orientações prestadas pelo enfermeiro na visita domiciliar ao idoso.

\section{Metodologia}

Trata-se de um estudo qualitativo, exploratório, descritivo e de pesquisa de campo. Considerando assim que alguns dos dados encontrados podem ser vistos de forma subjetiva e assim, a abordagem qualitativa se adequará melhor a proposta do estudo.

Atendendo aos princípios éticos da Resolução do Conselho Nacional de Saúde (CNS) nº.466/12, que assegura os direitos e deveres da comunidade científica e dos sujeitos da pesquisa, respeitando-se os princípios de justiça, equidade e segurança, este projeto foi encaminhado ao Conselho de Ética em Pesquisa (CEP) da Universidade Iguaçu conforme consta no CAAE 12886719.8.0000.8044, conforme Número do Parecer: 3.423.538, aprovado em 28 de junho de $2019^{14}$.

O cenário da pesquisa foi uma Clínica da Família, localizada no município de Nova Iguaçu, Baixada Fluminense/RJ, onde são oferecidos atendimentos de Psiquiatria, Dermatologista, Pediatria, Psicologia, Assistente Social, Ortopedista, Odontologia, Saúde da Mulher. Vale salientar que a instituição oferece toda a estrutura física, funcional, tecnológica, recursos humanos, modelos de gestão e assistência necessários para execução do projeto.

Cabe mencionar que os critérios de inclusão dos sujeitos foram: ser familiar ou acompanhante direto do idoso que esteja em condições mentais preservadas, ter disponibilidade para participar do estudo devidamente formalizado, e aceitem, de livre e espontânea vontade, participar desta pesquisa.

Em observância à legislação em pesquisa envolvendo seres humanos, os sujeitos da pesquisa assinaram o Termo de Consentimento Livre e Esclarecido. Antes foram informados sobre os objetivos da pesquisa, a participação voluntária, o direito ao anonimato, e sigilo dos dados informados, além do direito de abandonar a pesquisa em qualquer etapa se assim desejarem.

A coleta de dados foi realizada através de uma entrevista semiestruturada, norteada por um questionário. Durante as entrevistas e análise de dados, foram respeitados os valores culturais, sociais, morais, religiosos e éticos, assim como os hábitos e costumes dos sujeitos da pesquisa em assinatura do Termo de Consentimento Livre e Esclarecido.

$\mathrm{O}$ número de participantes alcançados ao final da coleta de dados foi de 17 indivíduos. A abordagem aos possíveis sujeitos da pesquisa foi realizada durante a visita domiciliar de cadastrados na clínica da Família Cerâmica nos horários destinados para visita marcada pelos Agentes Comunitários de Saúde e pelo enfermeiro da unidade.

Foram previstos procedimentos que assegurassem a confidencialidade e privacidade, a proteção da imagem e a não estigmatização, garantindo a não utilização das informações em prejuízo das pessoas, incluindo em termos de autoestima, de prestígio e/ou econômico financeiro. Para preservar a identidade dos sujeitos foram utilizados nomes comuns fictícios para a identificação das falas dos sujeitos.

Logo depois a coleta dos dados foi realizada a análise das entrevistas e a apresentação e descrição dos resultados. Foram transcritas as parcialidades gravadas das entrevistas e os entrevistados foram identificados com a letra "F", seguida do número correspondente ao mesmo. As entrevistas foram também impressas para facilitar a leitura, organização e análise das informações. Assim, realizou-se inicialmente uma leitura visando o contato com o material coletado e a elaboração de uma primeira impressão, que proporcionou uma familiaridade com os dados.

Após a identificação dos temas emergentes de cada entrevista, foram identificados os temas similares que apareceram com maior frequência nos discursos dos sujeitos. Nessa etapa, os temas foram destacados por meio de recortes de frases dos discursos.

\section{Análise de dados e discussão dos resultados}

Nesta etapa do estudo, foram analisados os dados e discutidos os resultados obtidos na pesquisa de campo, 
tendo como escopo trazer respostas à questão norteadora: Qual a ótica da família frente a visita domiciliar ao idoso realizada pelo enfermeiro na atenção primária? E que o familiar por sua vez consiga compreender de forma satisfatória os cuidados implantados. Para tanto, buscou-se utilizar de forma sistemática a aplicação da técnica de análise de conteúdo alicerçada nas bases conceituais legitimadas na obra apresentada pelo autor de referência, utilizando o referencial teórico e as indicações trazidas pela pesquisa de campo ${ }^{16}$.

Cabe mencionar que os participantes foram identificados pela letra "F" e números, seguindo a ordem de realização das entrevistas.

Gráfico 1. Classificação dos sujeitos do estudo em relação ao gênero.

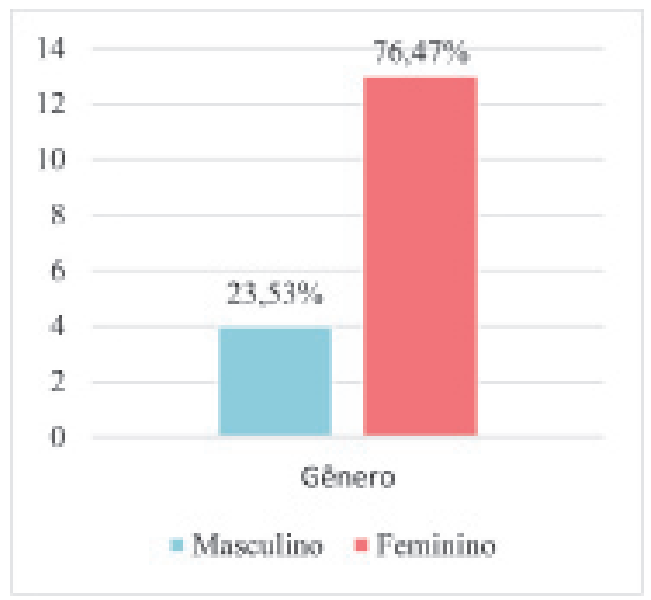

Fonte: Construção dos autores, 2019.

As atividades de cuidar sejam no âmbito familiar ou no âmbito institucional são desenvolvidas majoritariamente por mulheres, pois historicamente se lhes atribui certas qualidades inatas em oposição às qualificações aprendidas no espaço público ${ }^{17}$.

Gráfico 2. Classificação etária dos sujeitos do estudo.

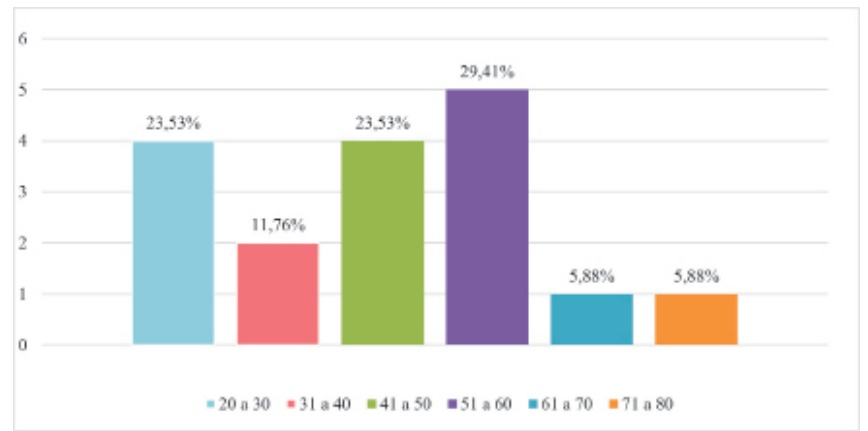

Fonte: Construção dos autores, 2019.

De acordo com o que se pode observar na Gráfico 2, fracionada em seis faixas etárias variáveis entre indivíduos maiores de 20 anos até indivíduos com mais de 70 anos, depreende-se que entre 51 e 60 anos correspondem à maioria dos familiares cuidadores.

Gráfico 3. Classificação dos sujeitos do estudo segundo o grau de escolaridade

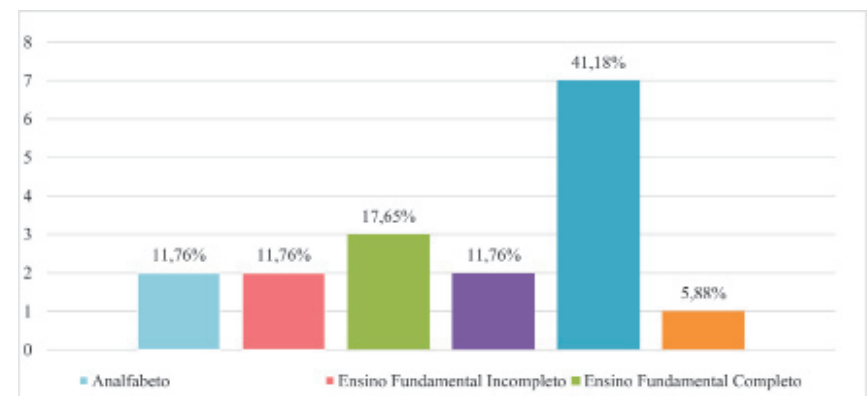

Fonte: Construção dos autores, 2019.

A mensuração do grau de escolaridade dos indivíduos entrevistados, conforme se pode observar na Gráfico 3 revelou que a maioria dos sujeitos representados possui nível médio completo. Em cinco polos opostos encontram-se aqueles com baixa escolaridade, ensino superior completo e um analfabeto.

Da leitura do material coletado surgiram três categorias: a primeira avalia o atendimento do enfermeiro, A segunda, refere-se à confiabilidade com os cuidados impostos pelo enfermeiro. As discussões finalizam com a terceira categoria: das possíveis dificuldades em entender as orientações que o enfermeiro repassa.

\section{Avaliação do familiar referente ao atendimento do enfermeiro}

É importante serviços de saúde abrangentes, não apenas curativos, mas também serviços que atendam às necessidades em termos de promoção da saúde, prevenção, reabilitação e tratamento de condições comuns. Um forte nível resolutivo de atenção primária de saúde é a base para o desenvolvimento de sistemas de saúde ${ }^{17}$.

Pressupõe que no momento do encontro entre a família do usuário e enfermeiro consiga captar as necessidades singulares da saúde do idoso, tornandose imprescindível uma abertura à escuta qualificada; implica acolher o outro, propiciar espaço para o diálogo, e estabelecer vínculo e laços de confiança ${ }^{18}$.

$\mathrm{O}$ ato de acolher requer uma escuta sensível, o compartilhamento de saberes entre família e enfermeiro, A avaliação que o familiar prioriza é vínculo, a forma com que se é abordado e o zelo que os profissionais desenvolvem conforme as visitas onde ambos interagem. Essa avaliação tem como intuito promover a melhoria da qualidade dos serviços ofertados à comunidade no geral e garantir a maior efetivação dos direitos dos 
usuários ${ }^{18}$.

Quando arguidos sobre a avaliação do familiar referente ao atendimento do enfermeiro, obteve- se as seguintes falas:

(F1): "Quando o enfermeiro vem aqui eu acho ele bem paciente".

(F4): "Das vezes que ele vem fazer a visita é ótimo, ele é atencioso minha filha".

(F8): "Quando ele vem nem sempre estou em casa, mas já tive aqui quando visitou uma vez, e foi ótimo, bastante proveitoso".

(F7): "O atendimento do enfermeiro aqui é tranquilo ele demora a vir mais quando vem, ele trata bem".

(F3): "Boa, mas aí só posso dizer da vacina, só veio na vacina. Talvez se solicitar até venha né, mas é porque não solicito também né”.

A estratégia da visita domiciliar tem como benefício a diminuição do número de atendimentos nas unidades de saúde, o que significa uma menor sobrecarga de atendimentos nas unidades, levando a menores necessidades de investimentos ${ }^{19}$.

\section{Confiabilidade com os cuidados orientados pelo enfermeiro durante a Visita Domiciliar ao idoso}

É necessário que os enfermeiros venham desenvolver conhecimentos técnicos especializados referentes ao envelhecimento e ao cuidado domiciliário, para compreender as necessidades apresentadas pelos pacientes e propor um cuidado condizente a estes e conhecer a família em todas as suas dimensões, mantendo fortalecido o vínculo de confiança e proximidade entre seus membros e ao processo de cuidado ${ }^{20}$.

Acontece que a família tem se preocupado e se ocupado no cuidado de seus membros idosos. Por isso, é de suma importância que os profissionais enfermeiros estabeleçam e fortaleçam uma relação mais estreita de parceria com os familiares cuidadores, visualizando-os como colaboradores e clientes, uma vez que agregam hábitos de vida semelhantes aos dos idosos sob seus cuidados $^{21}$.

De modo geral, com o seu saber teórico científico, o papel do enfermeiro é desenvolver atividades voltadas para o cuidado na visita domiciliar, este espaço favorece um cuidar que compreende mais que um momento tecnicista, mas uma atitude de envolvimento afetivo com o outro, fortalecendo o vínculo profissionalusuário, o enfermeiro tem a oportunidade de ouvir demandas, avaliar as condições de saúde físicas e psicoemocionais $^{22}$.
A relação com os cuidadores é de extrema importância, age como um facilitador, para a identificação de problemas e possibilidades de auxílio ao usuário em seus modos de levar a vida, incentivando que expressem suas preocupações e experiências no cuidado ao paciente e buscando, ainda, o conhecer mais profundamente, assim como um "conselheiro", por ouvir e acolher famílias em relação a preocupações e medos. A visita permite ao profissional e sua equipe uma maior aproximação à realidade em que vive o indivíduo ${ }^{23}$.

Quando arguidos sobre os cuidados orientados pelo enfermeiro durante a Visita Domiciliar ao idoso, obteve- se as seguintes falas:

(F5): "Sim, em nenhum momento me senti desconfortável durante esses anos".

(F6): "Sim, ele se preocupa tanto que as vezes parece que é da minha familia. Acho que todos deveriam ser assim".

(F7): "Sim, algumas vezes pergunto e fico bastante satisfeita com o que ele fala".

(F9): "Sim, porque ele explica as coisas muito bem”.

(F12): "Sim, me sinto confortável ele é atencioso".

A família é, geralmente, a primeira e a mais constante unidade de saúde para seus membros, sendo que a atenção prestada envolve ações de promoção da saúde, prevenção e tratamento de doenças, incluindo as de reabilitação. Geralmente a função de cuidador é assumida por uma única pessoa, denominada cuidador principal, seja por instinto, vontade, disponibilidade ou capacidade $^{24}$.

\section{Dificuldades de adesão as recomendações ofertadas pelo enfermeiro durante a visita domiciliar do idoso}

As dificuldades enfrentadas não se fundamentam apenas pelo entendimento das orientações dadas pelo enfermeiro, mas pela dificuldade em que o enfermeiro se encontra em relação a sua área de visita. À presença da violência na comunidade atrapalha a assistência dos profissionais, que muitas vezes são informados sobre as situações de risco que acontecem em determinadas regiões pelos usuários assistidos por elas. Dessa maneira, devido à presença de diversos tipos de violência e de tráfico de drogas, entre outros fatores que são causadores das dificuldades da efetivação do processo de trabalho feitos pelo enfermeiro ${ }^{25}$.

De acordo com os estudos revelam que as concepções do conceito de adesão são relativas, não há 
uma concordância firmada para este, nem uma estratégia validada para mensurar a adesão do familiar para o tratamento que envolve o idoso, podendo-se assim subestimar a taxa de incidência da não adesão.

Nesse sentido mesmo não havendo ainda uma padronização da avaliação da aderência ao familiar sobre os cuidados pontuados possíveis razões da má adesão ao tratamento, sendo elas a não compreensão ou violação das instruções e orientações dadas durante os cuidados.

Em suma, sobre o processo de cuidado, que podem acarretar modificações nas instruções dadas e prejudicar ou colocar em risco o familiar estresse humano como pode se ver, o cansaço, excesso de atividades e responsabilidades para o cuidador, relação familiar alterada devido à doença do paciente ou outros problemas do dia-a-dia e resistência ao tratamento por parte dos familiares (questões religiosas) ou por parte dos pacientes.

A visita domiciliar exige preparo profissional predisposição pessoal e disponibilidade de tempo na sua execução, por outro, é um serviço prestado dentro do próprio contexto, que parece agradar à maioria da população e pode diminuir a demanda pelas instituições de saúde, reduzindo custos para as famílias e o setor saúde ${ }^{26}$.

A atuação do enfermeiro na atenção primaria à saúde tem como propósito a realização das suas atividades baseado no conhecimento das ações a serem desenvolvidas, tendo que os profissionais carecem ter um olhar particular para todo cliente assistido. À vista disso, observa-se que é fundamental a aplicação de instrumentos que auxiliem o processo de assistencial no ambiente domiciliar, como a elaboração do vínculo por meio da boa dinâmica, buscando sempre aplicar a escuta e um bom acolhimento, visto isso realizando um atendimento e identificando os usuários com um todo e não focando exclusivamente sua patologia ${ }^{27}$.

Quando arguidos sobre dificuldades de adesão as recomendações ofertadas pelo enfermeiro durante a visita domiciliar do idoso, obteve- se as seguintes falas:

(F2): "Até que não, olha ele é bem objetivo. Ele explica as coisas e sempre dá vários exemplos, pergunta várias vezes se estou entendendo e as vezes, ainda me faz repetir o que ele acabou de explicar".

(F10): "Não, ele se esforça bastante pra sair daqui e deixar a todos sem dúvidas".

(F3): "Xiiii... hoje que ele veio pela primeira vez, até que consegui entender. Só acho que deveriam vir aqui mais vezes. Sempre temos algumas dúvidas e o enfermeiro poderia ser mais presente. ".

(F13): "Minha filha é a primeira vez dele aqui hoje. Só conhecia ele de nome, porque os ACS dizem que ele virá mas, sempre que agenda nunca comparece".
(F15): "Mais ou menos, porque ele não vem sempre, e quando vem a visita é muito rápida. Tenho a impressão que ele chega aqui já querendo ir embora".

Entende-se a importância do enfermeiro como educador na promoção da saúde, uma vez que é o profissional que possui conhecimentos técnicas e habilidades para realizar uma análise detalhada das condições do cliente idoso e do seu cuidador, atentar para as fragilidades e especificidades destes indivíduos, a fim de antecipar-se e intervir em possíveis complicações, para evitar que o estado de saúde piore e, assim, assegurar a qualidade de vida dos clientes ${ }^{28}$.

É por intermédio da visita que este profissional será apto de analisar as condições social e familiar em que vive o indivíduo, bem como fazer a busca ativa e idealizar e realizar as medidas assistenciais adequadas, com base na promoção da saúde. O enfermeiro realiza suas visitas domiciliar voltado não só pelo cliente, mas também para a sua à família ${ }^{29}$.

\section{Considerações Finais}

Em síntese este estudo salientou a seus realizadores lançar um olhar mais humanizado não apenas sobre aquele que necessita dos cuidados de enfermagem, mas incluir neste rol, também os familiares cuidadores. Eles recebem uma responsabilidade que inclui todo o seu tempo e sua estrutura física e emocional para cuidar do seu ente querido.

É indispensável que diante de dados e argumentos apresentados na pesquisa, tenhamos conhecimento sobre os problemas expostos. Em virtude disso, conclui-se que a maioria dos usuários entrevistados estão satisfeitos com a visita domiciliar do enfermeiro, entretanto não se exclui a considerável questão sobre a frequência da realização de visitas domiciliares que, na opinião da maioria dos entrevistados, não acontece como deveria ser.

Notou-se que, segundo os resultados obtidos, as visitas do enfermeiro no domicílio não são frequentes, entretanto quando realizadas, o enfermeiro esclarece as dúvidas e nessa perspectiva os resultados em termo são positivos. A visita ocorre na média uma a duas vezes ao mês, algumas famílias afirmam que uma visita ao mês é o necessário para o cuidado domiciliar.

Em virtude da nossa observação durante a coleta de dados os agentes comunitários não são compromissados com o enfermeiro em questão das visitas marcadas obtendo um déficit na conduta das estratégias. O que mais enfatizamos foi a confiança que o familiar deposita em toda equipe de saúde, sobre o posicionamento do enfermeiro que é de extrema importância sendo assim profissional, compromissado e empático.

Primordialmente a construção desse trabalho 
possibilitou um olhar mais profundo na atenção primaria à saúde e argumentar as estratégias promovidas na atenção do idoso, além dos idosos, ter uma percepção focada também no familiar, pois o índice de idosos no nosso país aumentou nos últimos anos suponho que seja consequência das estratégias de saúde organizadas pelo SUS, sendo preciso ter um visão direcionada a grande população idosa, e a visita é a continuidade do cuidado, é uma ponte entre a clínica e as famílias que são cadastradas englobando e dissipando a saúde nas famílias nas áreas territoriais necessitadas.

Por certo, a questão psicobiossocial, a saúde e doença são condições que estão em equilíbrio e estão codeterminadas por variáveis biológicas, psicológicas e sociais, todas em constante interação. O estudo, diagnóstico, prevenção e tratamento de várias doenças devem considerar as contribuições especiais e diferenciadas.

A melhor maneira de cuidar de pessoas que estão doentes se dá por ações integradas, realizadas por uma equipe de saúde, que deve ser composta por profissionais especializados. O modelo biopsicossocial pressupõe ações integradas e interdisciplinares. Porém, necessita de amadurecimento em função da formação dos profissionais de saúde, dos modelos de gestão, de financiamento e funcionamento do sistema de saúde como um todo.

Logo é gratificante para o paciente poder tratar a sua patologia no conforto do seu lar, pois na grande maioria das vezes apresenta resultados positivos e satisfatórios, seguindo sua rotina diária e interagindo com seus familiares e amigos, esse é um ponto importante para uma recuperação mais rápida e eficaz do doente, onde o enfermeiro deverá atuar sempre de forma humanizada, fazendo com que a família também participe no que for possível.

Este artigo refere se o olhar do familiar nas visitas domiciliares é um olhar inverso, pois o costume é ter artigos que falam sobre a visão do próprio enfermeiro, e olhar para família é ter mais um meio de implementar os cuidados que visam favorecer toda a família. É preciso obter mais artigos sobre a ótica do familiar frente a qualquer estratégia na atenção básica sobre o familiar dos idosos, para que outros profissionais da saúde leiam e até escrevam outros artigos sobre essa temática para mudar o posicionamento, e evitar fatores estressores sobre os mesmos, por consequência ter um aumento no índice de um envelhecimento saudável.

\section{Referências}

1. Sossai; LC; Pinto; ICA visita domiciliária do enfermeiro: fragilidades $\mathrm{x}$ potencialidades. 2014

2. Gago, A. E.; Lopes J. M. Cuidados domiciliares: interação do enfermeiro com a pessoa idosa/família. 2012

3. Martins, JJ. Políticas públicas de atenção à saúde do idoso: reflexão acerca da capacitação dos profissionais da saúde para o cuidado com o idoso. Rev Bras Geriatr Gerontol. 2007; 10(3)

4. Brasil. Ministério da Saúde. Orientações técnicas para a implementação de linha de cuidado para atenção integral à saúde da pessoa idosa no sistema único de saúde. Brasília: março; 2018.

5. Polero, SHI; Gonçalves, LHT; Alvarez AM. Enfermeiras desafiando a violência no âmbito de atuação da Estratégia de Saúde da Família. Text. Context. Enf., 2013; 22(4): 935-42

6. Azevedo, JMR; Barbosa MA. Triagem em serviços de saúde: percepções dos usuários. Rev enferm UERJ. 2012; 15:33-9.

7. Brasil. Ministério da Saúde. Orientações técnicas para a implementação de linha de cuidado para atenção integral à saúde da pessoa idosa no sistema único de saúde. Brasília: março; 2018.

8. Azevedo, JMR; Barbosa MA. Triagem em serviços de saúde: percepções dos usuários. Rev enferm UERJ. 2012; 15:33-9.

9. Azevedo, ALM; Costa AM. A estreita porta de entrada do Sistema Único de Saúde (SUS): uma avaliação do acesso na estratégia de saúde da família. Interface - Comunic., Saúde, Educ. 2010; 14:797-810

10. Alvez, Cândida; Melo, Michelle; Medeiros, Niedson; A importância da visita domiciliar ao paciente idoso. Anais CIEH (2015) - Vol. 2, N.1

11. Andrade AM, Silva KL, Seixas CT, Braga PP. Nursing practice in home care: an integrative literature review. Rev Bras Enferm [Internet]. 2017;70(1):210-217.

12. Brasil. Ministério da Saúde. Orientações técnicas para a implementação de linha de cuidado para atenção integral à saúde da pessoa idosa no sistema único de saúde. Brasília: março; 2018.

13. Costa, RHS; Couto, CRO; Silva, RAR. Prática clínica do enfermeiro na Estratégia de Saúde da Família. Rev. Enferm. Santa Maria. 2015; 41(2), Jul./Dez

14. Brasil, Ministério da Saúde. Conselho Nacional de Saúde, $\mathrm{n}^{\circ} .466 / 12.2012$

15. Gago, A. E.; Lopes J. M. Cuidados domiciliares: interação do enfermeiro com a pessoa idosa/família. 2012

16. Bardin, L. Análise de Conteúdo. Lisboa, Portugal; Edições 70, LDA, 2016.

17. Gomes, MFP; Fracolli, LA.; Machado, BC; Atenção domiciliar do enfermeiro na Estratégia de Saúde da Família, 2015.

18. Kawata, LS; Mishima, SM; Chirelli, MQ et al. Os desempenhos da enfermeira na saúde da família- Construindo competência para o cuidado. Texto Contexto Enf, Florianópolis, 2013; 22(4): 961-70.

19. Kebian, LVA; Acioli, AS. Visita Domiciliar de Enfermeiros e Agentes Comunitários de Saúde da Estratégia da Família. Rev. Elet. Enf., 2014; 403408

20. Kebian, LVA, Acioli, S. Visita Domiciliar: espaço de práticas de cuidado do enfermeiro e do agente comunitário de saúde. 2012

21. Martins, JJ; Schier J, Erdmann AL et al. Políticas públicas de atenção à saúde do idoso: reflexão acerca da capacitação dos profissionais da saúde para o cuidado com o idoso. Rev Bras Geriatr Gerontol. 2007; 10(3).

22. Minayo, Maria Cecília de Souza. O desafio do conhecimento: pesquisa qualitativa em saúde. In: O desafio do conhecimento: pesquisa qualitativa em saúde. 2014

23. Ministério da Saúde. Caderneta de saúde da pessoa idosa Brasília: Editora do Ministério da Saúde, 4 edição. 2017.

24. Nascimento. JS; Costa, LMC; Santos, RM et al. Visitas Domiciliares Como Estratégias de Promoção da Saúde pela Enfermagem. Rev. Bras. Promoc. Saúde, 2013; 26(4): 513-52

25. Polero, SHI; Gonçalves, LHT; Alvarez AM. Enfermeiras desafiando a violência no âmbito de atuação da Estratégia de Saúde da Família. Text. Context. Enf., 2013; 22(4): 935-42 
26. Silva, FAM. Ampliação do papel dos enfermeiros na atenção primária a saúde. 2018

27. Silvestre, Jorge Alexandre, Costa Neto, Milton Menezes. Abordagem do idoso em programas de saúde da família. Cad saúde pública.2013 mai/ jun;19(3):839-47.

28. Sossai; LC; Pinto; ICA visita domiciliária do enfermeiro: fragilidades x potencialidades. 2014

29. Tartuce, Gisela Lobo BP. Cuidado e cuidadoras: as várias faces do trabalho do care. Cad. Pesqui., São Paulo, 2013; 43(148): 366-372. 